\title{
Operation of an anaerobic filter and an EGSB reactor for the treatment of an oleic acid-based effluent: influence of inoculum quality
}

\author{
M.A. Pereira, M. Mota, M.M. Alves* \\ Centro de Engenharia Biológica-IBQF, Universidade do Minho, Campus de Gualtar, 4710-057 Braga, Portugal
}

Received 14 June 2001; accepted 16 October 2001

\begin{abstract}
An expanded granular sludge bed (EGSB) reactor and an anaerobic filter (AF), inoculated with granular and suspended sludge, respectively, were operated with an oleic acid-based synthetic effluent. The granular inoculum exhibited a specific methanogenic activity with acetate, ethanol and $\mathrm{H}_{2} / \mathrm{CO}_{2}$ as substrates, in average 2-7 times higher than the suspended biomass. Resistance to oleic acid toxicity was ten-fold higher in the granular than in the suspended sludge. Due to the better characteristics of the granular inoculum a faster start-up strategy was adopted in the EGSB than in the AF, being oleic acid fed since the beginning and the co-substrate eliminated on Day 70. In the AF, a co-substrate was fed until Day 150 and oleic acid was introduced only on Day 94. Organic loading rates of 8 and $12 \mathrm{~g} \mathrm{COD} / 1 \mathrm{~d}$ of oleate as the sole carbon source were achieved in the EGSB and AF, with removal efficiencies of 70 and $80 \%$, respectively. At these maximal loads, the average effluent volatile suspended solids were 2.7 and $5.6 \mathrm{~g} / \mathrm{l}$ in the EGSB and AF, respectively. The methane yield decreased from 280 to $271 \mathrm{CH}_{4} / \mathrm{kg}$ COD-removed in the EGSB and from 362 to $911 \mathrm{CH}_{4} / \mathrm{kg}$ COD-removed in the AF. The possibility of using a faster start-up procedure using a better inoculum was investigated and results suggest that inoculum quality was not, in this case, a dominant factor for the operation of reactors with high LCFA content. (C) 2002 Elsevier Science Ltd. All rights reserved.
\end{abstract}

Keywords: Anaerobic filter; Expanded granular sludge bed; Oleic acid; Long chain fatty acid

\section{Introduction}

Lipids are one of the major components of organic matter in wastewaters. Along with slaughterhouses and edible oil and fat refineries, dairy industries are important contributors for total lipid emission. In general, they are easily hydrolysed to long chain fatty acids (LCFA), which are further converted to acetate and hydrogen by acetogenic bacteria through a $\beta$-oxidation mechanism [1]. LCFAs are toxic at millimolar concentrations for both methanogens and acetogens, the two main groups involved in LCFA degradation $[2,3]$. However the most important problem that arises when sludge bed digesters are applied for the treatment of

\footnotetext{
* Corresponding author. Tel.: + 351-253-604402; fax: + 351-253678986.

E-mail address: madalena.alves@deb.uminho.pt (M.M. Alves).
}

lipid containing effluents, is the adsorption of a lipid layer around biomass particles causing biomass flotation and washout. In UASB reactors, sludge flotation occurs at concentrations far below the toxicity limit, which might suggest that complete washout of granular sludge would occur prior to inhibition [4]. Furthermore, addition of calcium salts prevents inhibition to some extent, but does not prevent flotation [5].

Hwu [4] concluded that for treating an oleate-based effluent, the typical expanded granular sludge bed (EGSB) operating conditions (superficial velocity $>4$ $\mathrm{m} / \mathrm{h}$ and HRT $<10 \mathrm{~h}$ ) inhibited treatment performance due to washout in particulate form and found the highest methane conversion for a HRT of $24 \mathrm{~h}$. In such systems, biomass immobilization is achieved by selfgranulation, a crucial requirement that, when unsuccessful, affects the overall performance most of times, irreversibly. Granular sludge is more resistant to LCFA toxicity than suspended or flocculent sludge but granu- 
lation and/or granule stability is very problematic for lipid containing wastewaters $[4,6,7]$.

As long as the support medium is efficient for biomass immobilization, the application of anaerobic filters (AFs) for the treatment of oleate-based effluents can be advantageous in comparison to sludge bed reactors. In such reactors, the biomass is immobilized by entrapment and adhesion in a support matrix, although the adhered fraction is only $10 \%$ in a reactor fed with an oleate-based synthetic effluent (PVC support matrix) [8]. Good stability and robustness can be pointed out as the main advantage of this system while channelling and clogging problems represent a major drawback.

There are some reports of the application of these technologies for the treatment of effluents with high lipid content. For an ice-cream wastewater, granulation was unsuccessful, and the fixed bed system was the most adequate for that kind of wastewater [6]. Rinzema concluded that the application of conventional UASB reactors to LCFA containing wastewaters resulted in local overloading of LCFA and severe washout caused by flotation. The EGSB reactor could however be applied with some design modifications by introducing a sieve-drum to prevent the washout of granular sludge [9]. Ruiz et al. compared an AF and an UASB reactor for the treatment of a slaughterhouse effluent and concluded that the UASB was the better choice [10].

In a previous work, when comparing the performance of different fixed bed digesters fed with oleic acid, inoculated with acclimatized and non-acclimatized

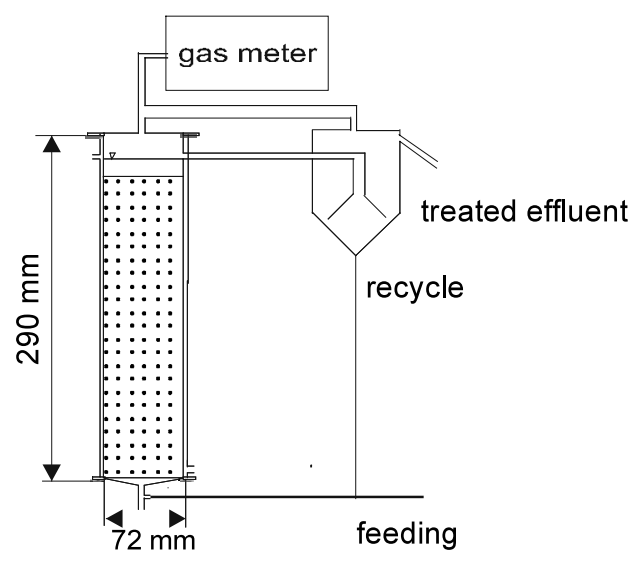

(a) sludge, it was concluded that acclimatization enables higher methanization and higher removal efficiencies than non-acclimatized sludge when similar operating conditions are applied [11].

The aim of this work was to operate an AF and an EGSB reactor for the treatment of an oleate-based synthetic effluent. Due to the different inoculum characteristics different start-up conditions were applied in each reactor. Sodium oleate was used as a model because it is, in general, the most abundant of all LCFA present in wastewater, has a good solubility and it is the most important LCFA produced by whole milk degradation $[5,12]$.

\section{Materials and methods}

\subsection{Experimental set-up}

The AF (R1), was constructed in Plexiglas and is schematically presented in Fig. 1a. The initial liquid volume was 11 and the support matrix consisted of PVC Raschig rings $21 \mathrm{~mm}$ in size, with a specific surface area of $230 \mathrm{~m}^{2} / \mathrm{m}^{3}$ and a porosity of $92.5 \%$. The external settler was constructed in Plexiglas and had a liquid volume of $200 \mathrm{ml}$. The EGSB reactor was also constructed in Plexiglas, had a volume of 101 and is presented in Fig. 1b. An internal settler allowed gassolid-liquid separation.

The substrate was stored at $4{ }^{\circ} \mathrm{C}$ in order to minimize acidification. Temperature was kept constant at $37 \pm 1{ }^{\circ} \mathrm{C}$.

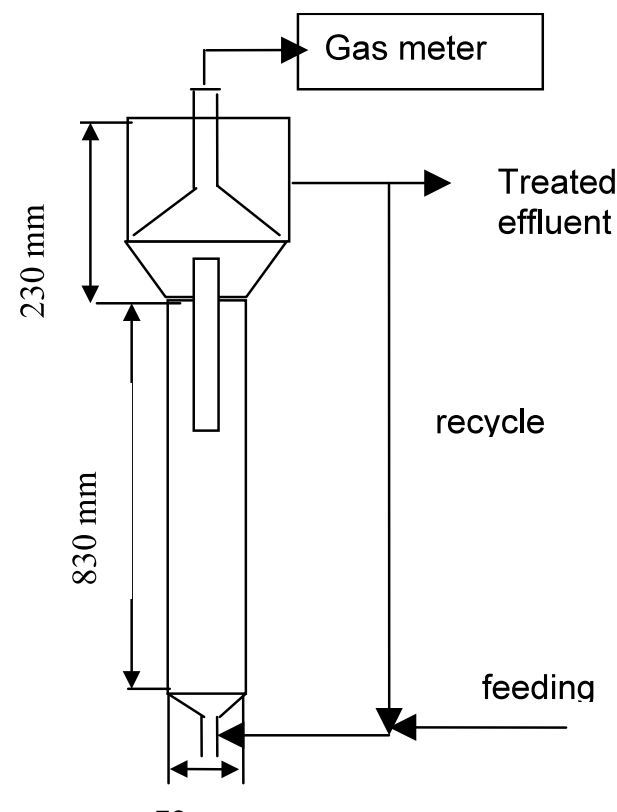

$72 \mathrm{~mm}$

(b)

Fig. 1. Experimental set-up. (a) AF, and (b) EGSB reactor. 


\subsection{Substrate}

Initially in the AF, the substrate was made by dilution of skim milk with tap water and was supplemented with macro and micronutrients. In the EGSB reactor, skim milk was also the co-substrate fed, but oleate was fed since the beginning. Macro and micronutrients had the following composition: macronutrients$\mathrm{MgCl}_{2} \cdot 6 \mathrm{H}_{2} \mathrm{O}: 25 \mathrm{~g} / 1 ; \mathrm{KH}_{2} \mathrm{PO}_{4}: 28.3 \mathrm{~g} / 1 ; \mathrm{KCl}: 45 \mathrm{~g} / 1$. This solution was added $0.6 \mathrm{ml}$ per $\mathrm{g}$ COD fed. Micronutrients [13] $-\mathrm{FeCl}_{2} \cdot 6 \mathrm{H}_{2} \mathrm{O}: 2 \mathrm{~g} / 1 ; \mathrm{ZnCl}_{2}: 0.05 \mathrm{~g} / 1$; $\mathrm{CuCl}_{2} \cdot 2 \mathrm{H}_{2} \mathrm{O}: \quad 0.038 \mathrm{~g} / \mathrm{l} ; \quad \mathrm{MnCl}_{2} \cdot 4 \mathrm{H}_{2} \mathrm{O}: 0.5 \mathrm{~g} / 1 ;$ $\mathrm{AlCl}_{3} \cdot 6 \mathrm{H}_{2} \mathrm{O}: 0.09 \mathrm{~g} / 1 ; \mathrm{CoCl}_{2} \cdot 6 \mathrm{H}_{2} \mathrm{O}: 2 \mathrm{~g} / 1 ; \mathrm{NiCl}_{2} \cdot 6 \mathrm{H}_{2} \mathrm{O}$ : $0.092 \mathrm{~g} / 1 ; \mathrm{Na}_{2} \mathrm{SeO}_{3} \cdot 5 \mathrm{H}_{2} \mathrm{O}: 0.164 \mathrm{~g} / 1$; EDTA: $1 \mathrm{~g} / 1$; Re-

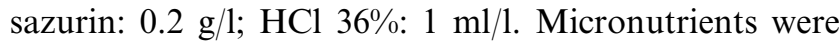
supplemented to the influent feed by addition of $1 \mathrm{ml} / 1$. To give suitable alkalinity, $5 \mathrm{~g} \mathrm{NaHCO}_{3}$ were added per litre of feed. In both reactors, skim milk was gradually replaced by oleate, attaining in the end a maximal concentration of $8 \mathrm{~g} \mathrm{COD} / 1$ as the sole carbon source in both digesters. In that situation, a nitrogen supplement of $98.9 \mathrm{~g} \mathrm{NH}_{4} \mathrm{Cl}$ was added per litre of macronutrients solution, in order to achieve a ratio $\mathrm{COD} / \mathrm{N} / \mathrm{P}$ of 250:5:1.1.

\subsection{Seed sludge}

The AF was seeded with $300 \mathrm{ml}$ of biomass $(25$ $\mathrm{g} \mathrm{VSS} / 1$ ) coming from a laboratory AF fed with skim milk as substrate for more than 900 days. The EGSB reactor was inoculated with 1.61 of granular sludge containing $18 \mathrm{~g} \mathrm{VSS} / 1$, which was collected at a full scale UASB reactor from a brewery company.

\subsection{Routine analysis}

Routine reactor performance was monitored by measuring the influent and the effluent total and soluble (centrifuged $10 \mathrm{~min}$ at $15000 \mathrm{rpm}$ ) chemical oxygen demand (COD), influent flow rate, effluent volatile fatty acids (VFA), methane production and volatile suspended solids (VSS). COD and VSS were determined according to standard methods [14]. VFAs (acetic, propionic and butyric) were determined by high-performance liquid chromatography using a Chrompack column $\left(300 \times 6.5 \mathrm{~mm}^{2}\right)$ and a mobile phase of $5 \mathrm{mM}$ sulphuric acid $\left(\mathrm{H}_{2} \mathrm{SO}_{4}\right)$ at $0.7 \mathrm{ml} / \mathrm{min}$. The column was set at $40{ }^{\circ} \mathrm{C}$ and the detection was spectrophotometric at $220 \mathrm{~nm}$. Methane content of the biogas was measured by gas chromatography using a Chrompack Haysep Q (80-100 mesh) column, with $\mathrm{N}_{2}$ carrier gas at 30 $\mathrm{ml} / \mathrm{min}$ and a flame-ionization detector. Temperatures of the injection port, column, and flame-ionization detector were 120,40 , and $130{ }^{\circ} \mathrm{C}$, respectively.

\subsection{Methanogenic activity, toxicity and biodegradability batch experiments}

Methanogenic activity, toxicity and biodegradability batch experiments were performed using a pressure transducer technique [15-17]. The methanogenic activity test involves monitoring the pressure increase developed in sealed vials fed with non-gaseous substrates or the pressure decrease in vials previously pressurized with gaseous substrates $\left(\mathrm{H}_{2} / \mathrm{CO}_{2}\right)$. The non-gaseous substrates were acetate, propionate, butyrate and ethanol. Strict anaerobic conditions were maintained. The hand held pressure transducer was capable of measuring a pressure increase or decrease of two bar ( 0 to $\pm 202.6 \mathrm{kPa}$ ) over a range of -200 to $+200 \mathrm{mv}$, with a minimum detectable variation of 0.005 bar, corresponding to $0.05 \mathrm{ml}$ biogas in $10 \mathrm{ml}$ headspace. A sensing element consisting of a $2.5 \mathrm{~mm}$ square silicon chip with integral sensing diaphragm is connected to a digital panel meter module and the device is powered by a $7.5 \mathrm{~V}$ DC transformer. The basal medium used in the batch experiments, made up with demineralized water, was composed of cysteine-HCL $(0.5 \mathrm{~g} / \mathrm{l})$ and sodium bicarbonate $(3 \mathrm{~g} / \mathrm{l})$, the $\mathrm{pH}$ was adjusted to 7.0-7.2 with $\mathrm{NaOH} 8 \mathrm{~N}$ and was prepared under strict anaerobic conditions. No calcium or trace-nutrients were added.

In the methanogenic toxicity tests, the oleate concentration ranged from 100 to $900 \mathrm{mg} / \mathrm{l}$ and acetate was added as co-substrate, in order to evaluate the influence of oleate concentration on the acetoclastic activity. Fifty percent inhibition concentration (IC50) was defined as the oleate concentration that caused a $50 \%$ relative methanogenic acetoclastic activity loss. Biodegradability tests were performed by adding increasing oleate concentrations $(100,300,500,700$ and $900 \mathrm{mg} / \mathrm{l})$ to the sludge in batch vials. All batch tests were performed in triplicate assays.

\subsection{Operation mode}

During the start-up, the AF was fed with skim milk (Period I). After this period, a mixture of skim milk with sodium oleate was used, with increasing oleate concentrations at a constant organic loading rate (Period II). During Period III, oleate was the sole carbon source fed (Table 1). The recycle flow was set at $15 \mathrm{l} / \mathrm{d}$. The EGSB reactor was operated in four distinct periods. During the start-up the substrate consisted of skim milk (50\% COD) and sodium oleate (50\% COD). From Day 70 on, oleate became the sole carbon source fed at concentrations of 4,6 and $8 \mathrm{~g} \mathrm{COD} / 1$. The HRT was set at $1 \mathrm{~d}$ over all the trial period (Table 2). The recycle flow was set at $14 \mathrm{l} / \mathrm{d}$. 
Table 1

Characteristic operation periods of both digesters

\begin{tabular}{lllll}
\hline Period & Time (d) & \multicolumn{2}{l}{$\begin{array}{l}\text { Type of substrate content } \\
\text { and concentration }(\mathrm{g} \text { COD } / \mathrm{l})\end{array}$} & HRT (h) \\
\cline { 3 - 4 } & & Skim milk & Oleate \\
\cline { 3 - 4 } AF & & & & \\
I & $0-44$ & 2 & - & $3.3-0.64$ \\
& $44-80$ & 2 & - & 0.64 \\
& $80-94$ & 4 & - & 0.64 \\
II & $94-105$ & 3 & 1 & 0.64 \\
& $105-119$ & 2 & 2 & 0.64 \\
& $119-150$ & 1 & 3 & 0.64 \\
III & $150-205$ & - & 4 & 0.64 \\
& $202-233$ & - & 8 & 0.64 \\
EGSB & & & & \\
I & $0-70$ & 2 & 2 & 1 \\
II & $70-119$ & - & 4 & 1 \\
III & $119-162$ & - & 6 & 1 \\
IV & $162-219$ & - & 8 & 1 \\
\hline
\end{tabular}

Table 2

Methanogenic activity and oleic acid toxicity for the granular and suspended seed sludge inoculated in the EGSB and in the AF, respectively $( \pm 95 \%$ confidence interval)

\begin{tabular}{lll}
\hline & $\begin{array}{l}\text { Granular (EGSB) } \\
(\mathrm{ml} \mathrm{CH}\end{array}$ & $\begin{array}{l}\text { Suspended (filter) } \\
(\mathrm{g} \text { VSS d) } \\
\left(\mathrm{ml} \mathrm{CH}_{4(\mathrm{STP})} / \mathrm{g} \mathrm{VSS} \mathrm{d}\right)\end{array}$ \\
\hline $\begin{array}{l}\text { Methanogenic } \\
\text { activity in the } \\
\text { presence of }\end{array}$ & & \\
$\begin{array}{l}\text { Acetate } \\
\text { Propionate }\end{array}$ & $327 \pm 11$ & $165 \pm 24$ \\
$\begin{array}{l}\text { Butyrate } \\
\text { Ethanol }\end{array}$ & $160 \pm 10$ & (n.d.) \\
$\mathrm{H}_{2} / \mathrm{CO}_{2}$ & $514 \pm 94$ & (n.d.) \\
Oleic acid toxicity & $345 \pm 26$ & $77.3 \pm 16.7$ \\
$\quad$ limit $\left(\mathrm{IC}_{50}\right)(\mathrm{mg} / \mathrm{l})$ & & $146.9 \pm 16.6$ \\
\end{tabular}

STP, standard temperature and pressure conditions; n.d., non-detectable.

\section{Results and discussion}

Prior to inoculation both sludges were characterized in terms of methanogenic activity, oleic acid toxicity and biodegradability (Table 2Fig. 2).

The granular inoculum exhibited a specific methanogenic activity with acetate, ethanol and $\mathrm{H}_{2}$ / $\mathrm{CO}_{2}$ as substrates, in average 2-7 times higher than the suspended one. The methanogenic activity with propionate as substrate was not detectable in the suspended sludge, whereas a value of $160 \mathrm{ml} \mathrm{CH}_{4(\mathrm{STP})} / \mathrm{g}$ VSS was measured for the granular sludge. Resistance to oleic acid toxicity was ten-fold higher in the granular than in the suspended sludge. From the biodegradability batch experiments, it is evident that in the granular sludge, practically no lag phases were detected, whereas in the suspended sludge lag-phases up to $300 \mathrm{~h}$ preceded the initial methane production (Fig. 2).

Due to the better characteristics exhibited by the granular inoculum in the batch assays, the EGSB was started-up at higher oleate loading rates than the AF. Oleic acid was fed since the beginning and the co-substrate was eliminated on Day 70. In the AF a co-substrate was fed until Day 150 and oleic acid was introduced only on Day 94 (Fig. 3a and b).

Tables 3 and 4 summarize the average pseudo steadystate values in the AGSB and AF, respectively.

Organic loading rates of 8 and $12 \mathrm{gCOD} / 1 \mathrm{~d}$ of oleate as the sole carbon source were attained in the EGSB and AF, with average removal efficiencies of 70 and $80 \%$, respectively. At these maximal loads, the average effluent VSS were 2.7 and $5.6 \mathrm{~g} / 1$ in the EGSB and AF, respectively. In spite of the strong washout detected in the AF at the maximal loading rate, in average, the effluent VSS values were lower than the measured for the EGSB reactor (Fig. 3c, Tables 3 and 4). When oleate became the sole carbon source fed to the EGSB reactor, on Day 70, a sharp decrease on the removal efficiency was observed from 98 to a minimum of $72 \%$ with a further recovery to $92 \%$.
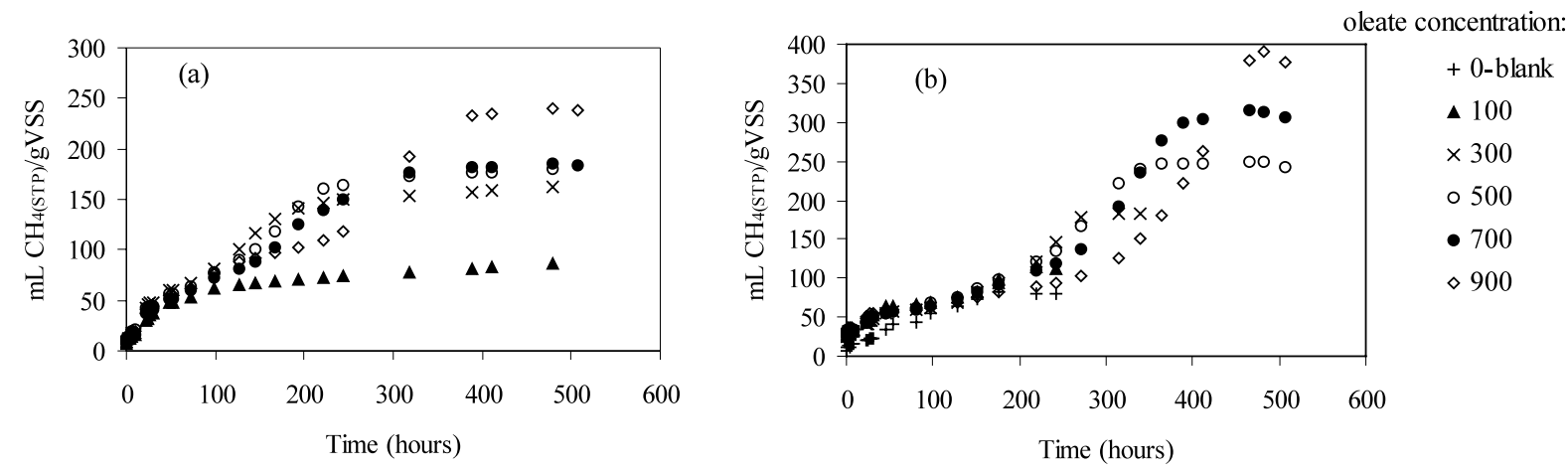

Fig. 2. Results from the biodegradability tests. (a) Granular sludge, and (b) suspended sludge. 


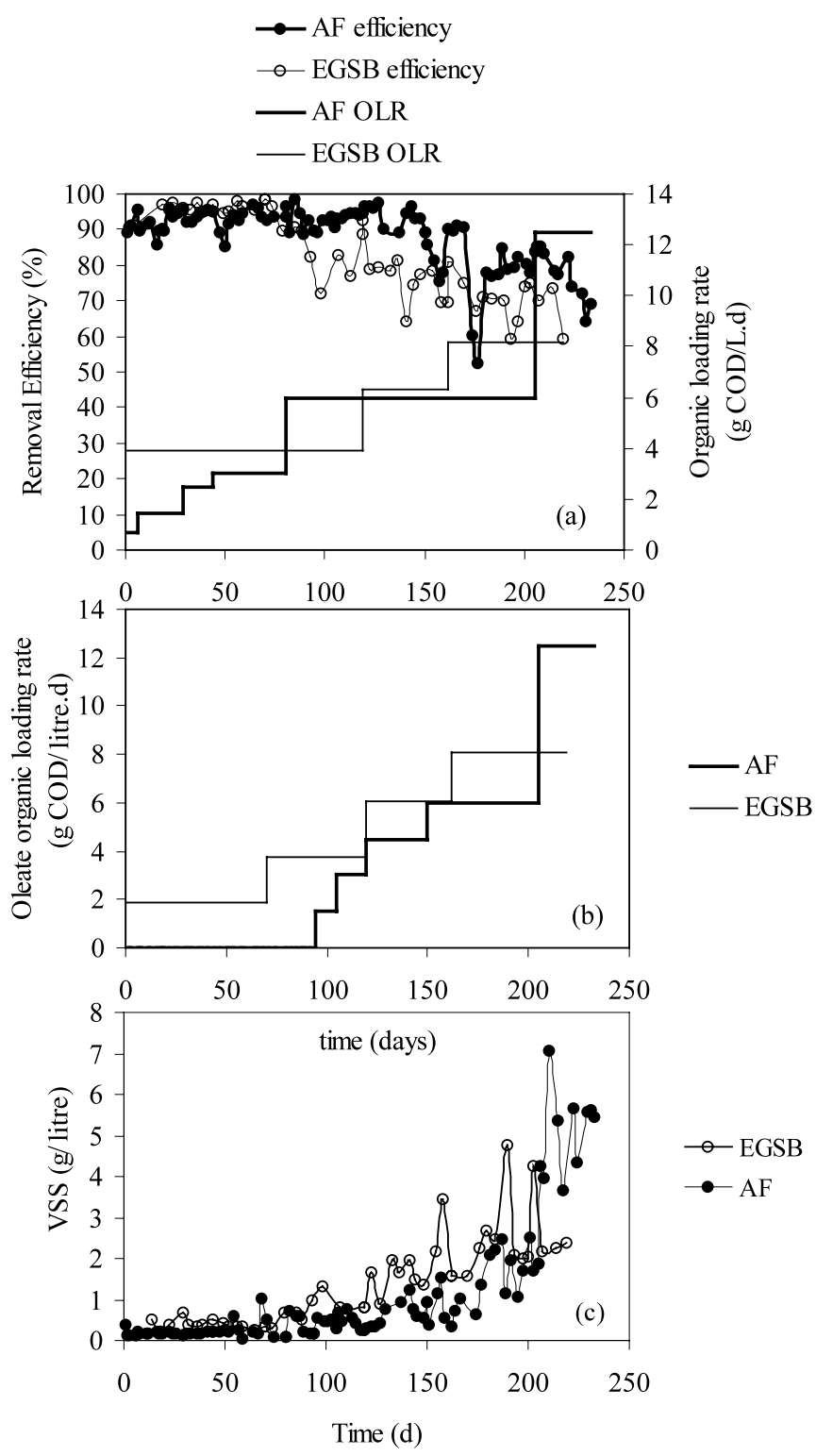

Fig. 3. Operating conditions and performance of the AF and the EGSB reactor. (a) Applied organic loading rate and COD removal efficiency, (b) applied oleate organic loading rate, and (c) effluent VSS.

The performance of the two reactors can be discussed from different viewpoints. Removal efficiency includes adsorption, precipitation with divalent cations and ef- fective biodegradation phenomena [4,18]. LCFAs adsorb onto the sludge causing biomass flotation and washout and partial precipitation of oleic acid by divalent ions, such as calcium or magnesium, lowers their soluble (available) concentration through the production of a calcium and magnesium-oleate precipitate. Methane yield refers only to the fraction of COD removed that is effectively methanized. The methane yield decreased from 280 to $271 \mathrm{CH}_{4} / \mathrm{kg} \mathrm{COD}$-removed in the EGSB and from 362 to $911 \mathrm{CH}_{4} / \mathrm{kg} \mathrm{COD-re-}$ moved in the AF (Fig. 4).

The better methanization achieved in the AF than in the EGSB reactor, indicated that more oleate was retained in the EGSB than in the AF by mechanisms of adsorption and precipitation. The better performance of the AF can be related to the lower ratio between the oleate and divalent cations fed during the trial period. It is known that the presence of calcium can lead to a decrease of LCFA inhibitory effect, by lowering their soluble concentration through the production of a calcium-LCFA precipitate. The 'free' oleate concentration depends on oleate and calcium concentration in the feed and on the solubility product of the calcium oleate salt [18]. Since each divalent ion can theoretically precipitate two oleate molecules, a total precipitation of the existing oleate would be possible for a molar ratio under two. Considering that magnesium ion can exhibit a similar effect, the molar ratio oleate $/\left(\mathrm{Ca}^{2+}+\mathrm{Mg}^{2+}\right)$ was determined along the trial period and increased from 1 to 6.8 in the $\mathrm{AF}$, exceeding the stoichiometric value of 2 only after Day 119. In the EGSB, the value ranged from 2.1 to 6.9 , exceeding the stoichiometric value of 2 throughout all the trial period.

Adsorption depends on the available surface with the expectation that suspended sludge was more favourable for oleate adsorption due to the higher specific surface area. The adsorption phenomenon of LCFA onto anaerobic sludge has been described in previous works. Rinzema found that, beside the accumulation of a LCFA precipitate in a UASB reactor, biomass aggregates coated with the same precipitate were observed [9]. Also Hanaki et al. observed that LCFA resulting from the degradation of a lipidic substrate adhered onto the biomass in less of $24 \mathrm{~h}$ [5]. Hwu studied the adsorption of LCFA in granular sludge and concluded

Table 3

Pseudo steady-state operating conditions and performance data of the EGSB reactor, during each operation period ( $\pm 95 \%$ confidence interval)

\begin{tabular}{llllllll}
\hline Period & Time (d) & $\begin{array}{l}\text { HRT (d) } \\
( \pm 0.01)\end{array}$ & $\begin{array}{l}\text { Organic loading rate } \\
(\mathrm{g} \mathrm{COD} / \mathrm{d})\end{array}$ & $\begin{array}{l}\text { Removal efficiency } \\
(\%)\end{array}$ & $\begin{array}{l}\text { Biogas } \\
(\mathrm{l} / \mathrm{ld})\end{array}$ & $\begin{array}{l}\mathrm{CH}_{4} \\
(\%)\end{array}$ \\
\hline I & {$[0-70]$} & 1.01 & $3.9 \pm 0.3$ & $96.5 \pm 0.6$ & $1.51 \pm 0.1$ & $69.9 \pm 5.3$ & $0.38 \pm 0.07$ \\
II & {$[70-119]$} & 1.01 & $3.9 \pm 0.3$ & $83.4 \pm 4.8$ & $0.33 \pm 0.05$ & $68.9 \pm 4.0$ & $0.85 \pm 0.22$ \\
III & {$[119-162]$} & 1.01 & $6.3 \pm 0.7$ & $74.2 \pm 3.8$ & $0.23 \pm 0.02$ & $69.5 \pm 3.9$ & $1.96 \pm 0.43$ \\
IV & {$[162-219]$} & 1.01 & $8.2 \pm 2.7$ & $68.8 \pm 3.4$ & $0.22 \pm 0.02$ & $70.2 \pm 3.3$ & $2.71 \pm 0.57$ \\
\hline
\end{tabular}


Table 4

Pseudo steady-state operating conditions and performance data of the AF, during each operation period ( $\pm 95 \%$ confidence interval)

\begin{tabular}{|c|c|c|c|c|c|c|c|}
\hline & $\begin{array}{l}\text { Time } \\
\text { (d) }\end{array}$ & $\begin{array}{l}\text { HRT } \\
\text { (d) }\end{array}$ & $\begin{array}{l}\text { Organic loading rate } \\
\text { (g COD } / 1 \mathrm{~d})\end{array}$ & $\begin{array}{l}\text { Removal efficiency } \\
(\%)\end{array}$ & $\begin{array}{l}\text { Biogas } \\
(1 / 1 \text { d) }\end{array}$ & $\begin{array}{l}\mathrm{CH}_{4} \\
(\%)\end{array}$ & $\begin{array}{l}\text { Effluent VSS } \\
(\mathrm{g} / \mathrm{l})\end{array}$ \\
\hline \multirow[t]{5}{*}{ I } & {$[1-6]$} & $3.29 \pm 0.08$ & $0.67 \pm 0.03$ & $92.4 \pm 2.1$ & $(*)$ & $(*)$ & $0.14 \pm 0.04$ \\
\hline & [6-29] & $1.56 \pm 0.02$ & $1.41 \pm 0.05$ & $91.9 \pm 2.2$ & $(*)$ & $38.4 \pm 4.1$ & $0.18 \pm 0.06$ \\
\hline & [29-44] & $1.01 \pm 0.01$ & $2.18 \pm 0.08$ & $94.8 \pm 0.6$ & $(*)$ & $55.4 \pm 8.1$ & $0.19 \pm 0.01$ \\
\hline & [44-80] & $0.64 \pm 0.01$ & $3.44 \pm 0.13$ & $93.9 \pm 0.9$ & $1.04 \pm 0.36$ & $60.7 \pm 3.8$ & $0.31 \pm 0.18$ \\
\hline & [80-94] & $0.64 \pm 0.01$ & $6.00 \pm 0.14$ & $92.8 \pm 3.1$ & $2.36 \pm 0.27$ & $60.5 \pm 6.6$ & $0.32 \pm 0.14$ \\
\hline \multirow[t]{3}{*}{ II } & [94-105] & $0.64 \pm 0.01$ & $6.00 \pm 0.14$ & $92.3 \pm 1.1$ & $2.82 \pm 0.25$ & $71.1 \pm 3.8$ & $0.44 \pm 0.08$ \\
\hline & [105-119] & $0.64 \pm 0.01$ & $6.00 \pm 0.14$ & $94.5 \pm 0.2$ & $2.32 \pm 0.19$ & $64.8 \pm 2.7$ & $0.46 \pm 0.17$ \\
\hline & [119-150] & $0.64 \pm 0.01$ & $6.00 \pm 0.14$ & $93.3 \pm 2.0$ & $1.55 \pm 0.14$ & $67.2 \pm 2.5$ & $0.72 \pm 0.21$ \\
\hline \multirow[t]{2}{*}{ III } & [150-205] & $0.64 \pm 0.01$ & $6.00 \pm 0.14$ & $81.7 \pm 2.4$ & $1.45 \pm 0.16$ & $68.5 \pm 3.9$ & $1.5 \pm 0.4$ \\
\hline & [205-233] & $0.64 \pm 0.01$ & $12.47 \pm 0.22$ & $80.4 \pm 2.6$ & $1.33 \pm 0.09$ & $68.3 \pm 6.7$ & $5.6 \pm 1.1$ \\
\hline
\end{tabular}

$(*)$ Not determined.

that, after adsorption, a partial desorption promoted by biogas release was observed [4]. Alves et al. observed that, after feeding a reactor with oleate as the sole carbon source, the biomass, after being washed several times with anaerobic buffer, still exhibited high methane production due to the degradation of the adsorbed substrate [3].

The operation of the EGSB reactor was dominated by the expected granular sludge disintegration and flotation, observed before [7,4]. A floating layer was located in the top of the reactor, but internal and external circulation allowed in some extent the maintenance of solids inside the reactor. This procedure was also referred before as a way to enhance LCFA degradation in continuous reactors [4].

At the end of the operation the capacity of methane production from the adsorbed substrate was assessed in batch assays. The biomass was washed and centrifuged twice with anaerobic buffer and incubated in batch vials without any added substrate (Fig. 5)

These results evidence the higher capacity of the biomass from the AF to produce methane from the adsorbed substrate. In the EGSB reactor, both top and bottom layers did not show any methane production capacity, at least in the first $200 \mathrm{~h}$. This agrees with the better performance exhibited in general by the AF, possibly due to the more gradual process of acclimatization to oleic acid with the presence of a co-substrate for a longer time during the start-up of this reactor, in comparison with the criteria followed to start-up the EGSB. The importance of the co-substrate for the treatment of effluents with a high LCFA content has already been evidenced [4].

\section{Conclusions}

An AF and an EGSB reactor were operated with an oleic acid-based effluent. Start-up strategy of each reactor was based on the different quality of the corre- sponding inocula. In the EGSB reactor, a granular sludge was inoculated that exhibited a specific methanogenic activity with acetate, ethanol and $\mathrm{H}_{2}$ / $\mathrm{CO}_{2}$ as substrates, in average 2-7 times higher and a resistance to oleic acid toxicity ten-fold higher than the suspended sludge inoculated in the AF.

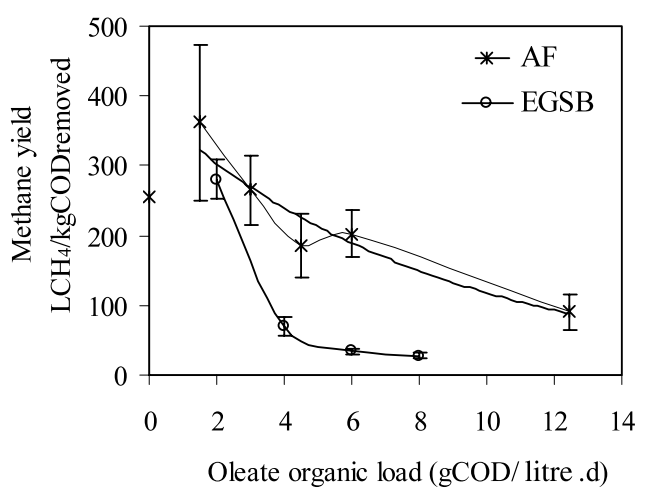

Fig. 4. Influence of the oleate organic load on the methane yield in the AF and EGSB reactors.

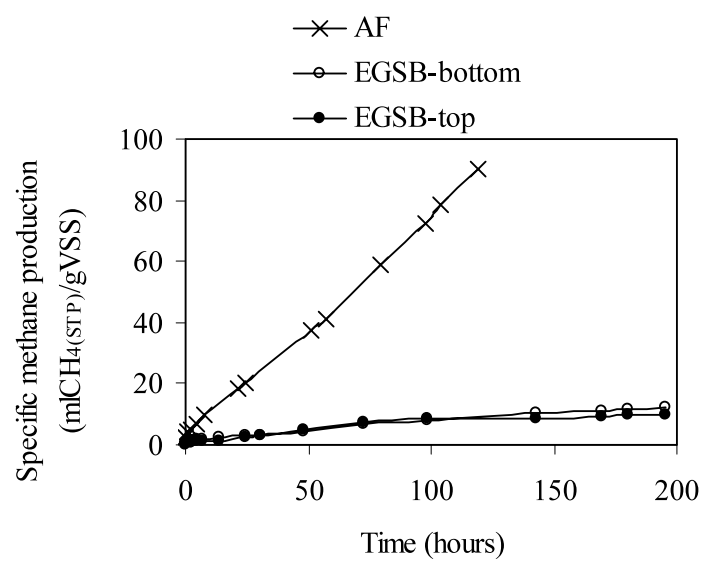

Fig. 5. Specific methane production due to the adsorbed substrate onto the biomass taken at the end of the operation from the AF and from the EGSB reactor. 
In the EGSB, oleic acid was fed since the beginning, the co-substrate was eliminated on Day 70 , and in the AF a co-substrate was fed until Day 150 and oleic acid was introduced only on Day 94. Although the final value was similar for both reactor (6.9 moles oleate/ mole $\left(\mathrm{Ca}^{2+}+\mathrm{Mg}^{2+}\right)$, higher molar ratios oleate $/\left(\mathrm{Ca}^{2+}\right.$ $+\mathrm{Mg}^{2+}$ ) were applied in the EGSB in the beginning. Organic loading rates of 8 and $12 \mathrm{~g} \mathrm{COD} / 1 \mathrm{~d}$ of oleate as the sole carbon source were attained in the EGSB and AF, with removal efficiencies of 70 and $80 \%$, respectively. At these maximal loads, the average effluent VSS were 2.7 and $5.6 \mathrm{~g} / 1$ in the EGSB and AF, respectively. The methane yield decreased from 280 to $271 \mathrm{CH}_{4} / \mathrm{kg}$ COD-removed in the EGSB and from 362 to $911 \mathrm{CH}_{4} / \mathrm{kg} \mathrm{COD}$-removed in the AF. At the end of the experiment, the sludge taken from the filter was able to produced methane from the adsorbed substrate at a rate of $20 \mathrm{ml} \mathrm{CH}_{4} / \mathrm{g} \mathrm{VSS} \mathrm{d}$, whereas in the EGSB complete inhibition was observed without any methane production in the first $200 \mathrm{~h}$.

The possibility of using a faster start-up procedure using a better inoculum was investigated and results suggest that inoculum quality was not, in this case, a dominant factor for the operation of reactors with high LCFA content.

\section{References}

[1] Weng C-N, Jeris JS. Biochemical mechanisms in the methane fermentation of glutamic and oleic acids. Wat Res 1976;10:918.

[2] Koster IW, Cramer A. Inhibition of methanogenesis from acetate in granular sludge by long-chain fatty acids. Appl Environ Microbiol 1987;53:403-9.

[3] Alves MM, Mota Vieira JA, Álvares Pereira RM, Pereira MA, Mota M. Effect of lipids and oleic acid on biomass development in anaerobic fixed-bed reactors. Part II: oleic acid toxicity and biodegradability. Wat Res 2001;35(1):264-70.

[4] Hwu C-S. Enhancing anaerobic treatment of wastewaters containing oleic acid. PhD Thesis. Wagningen, The Netherlands: Wageningen Agricultural University; 1997.
[5] Hanaki K, Matsuo T, Nagase M. Mechanisms of inhibition caused by long chain fatty acids in anaerobic digestion process. Biotechnol Bioeng 1981;23:1591-610.

[6] Hawkes FR, Donnely T, Anderson GK. Comparative performance of anaerobic digesters operating on ice-cream wastewater. Wat Res 1995;29:525-33.

[7] Sam-Soon P, Loewenthal RE, Wentzel MC, Marais GVR. A long-chain fatty acid, oleate, as sole substrate in upflow anaerobic sludge bed (UASB) reactor systems. Water SA 1991;17:31-6.

[8] Alves MM, Mota Vieira JA, Álvares Pereira RM, Pereira MA, Mota M. Effect of lipids and oleic acid on biomass development in anaerobic fixed-bed reactors. Part I: biofilm growth and activity. Wat Res 2001;35(1):255-63.

[9] Rinzema A. Anaerobic treatment of wastewater with high concentration of lipids or sulfate. PhD Thesis. Wagningen, The Netherlands: Wageningen Agricultural University; 1988.

[10] Ruiz I, Veiga MC, de Santiago P, Blázquez R. Treatment of slaughterhouse wastewater in a UASB reactor and an anaerobic filter. Biores Technol 1997;60:251-8.

[11] Pereira MA, Mota M, Alves MM. Degradation of oleic acid in anaerobic filters: effect of inoculum acclimatization and biomass recirculation. Wat. Environ. Res. 2001 (in press).

[12] Komatsu T, Hanaki K, Matsuo T. Prevention of lipid inhibition in anaerobic processes by introducing a two-phase system. Wat Sci Technol 1991;23(7/9):1189-200.

[13] Zehnder AJB, Huser BA, Brock TD, Wuhrmann K. Charaterization of an acetate-decarboxylating, non-hydrogen-oxidizing methane bacterium. Arch Microbiol 1980;124:1-11.

[14] APHA, AWWA, WPCF standard methods for the examination of water and wastewater, 17th ed. Washington; 1989.

[15] Colleran E, Concannon F, Goldem T, Geoghegan F, Crumlish B, Killilea E, et al. Use of methanogenic activity tests to characterize anaerobic sludges, screen for anaerobic biodegradability and determine toxicity thresholds against individual anaerobic trophic groups and species. Wat Sci Technol 1992;25(7):31-40.

[16] Coates JD, Coughlan MF, Colleran E. Simple method for the measurement of the hydrogenotrophic methanogenic activity of anaerobic sludges. J Microbiol Meth 1996;26:237-46.

[17] Colleran E, Pistilli A. Activity test system for determining the toxicity of xenobiotics chemicals to the methanogenic process. Ann Microbiol Enzymol 1994;44:1-20.

[18] Roy F, Albagnac G, Samain E. Influence of calcium addition on growth of highly purified syntrophic cultures degrading long chain fatty acids. Appl Environ Microbiol 1995;49(3): $702-5$. 